\title{
COMUniCAÇÃo E ARTE
}

\author{
Helena Pires, Silvana Mota-Ribeiro \& Anne Beyaert-Geslin
}

O presente número trinta e um da revista Comunicação e Sociedade incide, em particular, sobre o tema "Comunicação e Arte". Nesta mesma publicação, encontram-se reunidos textos que apresentam as mais diversas problemáticas, abordagens e metodologias, ensaiadas com base em modalidades e linguagens artísticas tão diferentes quanto a dança, o teatro, o cinema, as artes visuais. Os casos apresentados, bem como as manifestações artísticas em análise e reflexão, expressam uma polifonia cultural que combina o espaço lusófono, a herança cultural europeia, mas também a idiossincrasia da cultura e das artes em Portugal (dialogante com a esfera da interculturalidade), por meio de um recorte expressivo de algumas práticas, bem como do pensamento crítico que a área das artes, especialmente em articulação com a dimensão comunicativa, agiliza.

A reunião de uma tal pluralidade de perspetivas, tendo em vista a publicação em causa, convida a interpelarmo-nos sobre as possibilidades de sentido que este encontro, de textos, de autores, de realidades reportadas e objetos analisados, permite recriar. Qualquer compilação de textos de vários autores, mesmo que ancorada sobre um tema de algum modo partilhado, é sempre, arriscamos dizer, uma provocação, um espaço de encontro que desestabiliza os limites da significação prévia que cada texto preserva, na sua ilusória autonomia em termos intradiscursivos. Como não poderia deixar de ser, esta publicação é antes de mais inventora de sentidos, produtora de ligações, mas também de arrumações discutíveis, tendo por fim propor uma leitura, um exercício de hermenêutica que se deslocaliza da explicação da obra e do autor para a compreensão daquilo que mobilizou (e mobiliza) as editoras, elas mesmas implicadas numa ampla cartografia de inquietações, de problemas teóricos e metodológicos, partilhados entre a comunidade académica e a artística. É, pois, de uma aproximação entre a comunicação, nas suas possibilidades de interrogação sobre os públicos, a mediação, os discursos produzidos sobre o campo da cultura e das artes, por um lado, e a arte propriamente dita, nos seus desdobramentos intermodais e interdisciplinares, nos modos como convoca, cada vez mais, as competências e as potencialidades da comunicação, tanto na criação como na produção, por outro, que este número dá conta. Em última análise, tratar-se-á de discutir, pelo menos implicitamente, a porosidade de fronteiras entre a arte-ciência. Este debate é hoje tão mais pertinente quanto assistimos a uma crise ontológica e epistemológica profunda, transversal às mais variadas práticas e representações, sociais e culturais. Pensar a comunicação, no modo como interpela (ou se deixa interpelar pel)a arte, é o desafio que perseguimos e para o qual os textos aqui publicados, que passamos a apresentar nas suas linhas gerais, constituem estimulantes pontos de partida.

Passemos a esclarecer quais as diretrizes de sentido que presidiram ao alinhamento dos textos que aqui se apresentam, bem como à proposta de leitura que lhes permite 
de certo modo ressignificarem-se entre si. Não se trata de listar temas, ou sub-temas, antes de arriscar a sugestão de níveis de afinidade, mais ou menos explícitos, entre pequenos conjuntos de textos que permitem a identificação de uma dada coloração quando percecionados na sua articulação com a publicação integral.

Num primeiro momento, são introduzidos quatro textos que perspetivam, cada um no seu registo particular, as artes performativas. Mateus Yuri Passos, no seu texto "O mundo engarrafado e a arqueologia da encenação: gravações audiovisuais como registro de producções operísticas", propõe-se refletir sobre "o uso de gravações audiovisuais como documentos para análise de producções de ópera contemporâneas agrupadas pela crítica alemã sob o termo teatro de director [Regietheater]". A partir de uma análise detalhada de alguns excertos da obra operística $O$ Anel do Nibelungo, de Richard Wagner, o autor evidencia as diferenças ao nível da autonomia das dimensões que compõem a obra integral (verbal, musical e visual) quando comparadas a encenação e a respetiva gravação, contribuindo assim para a compreensão das especificidades do meio, especialmente nas suas implicações no que à direção diz respeito. Segue-se o texto de Né Barros, intitulado "Dança e medialidade: para uma discussão ontológica e ética do corpo performativo". Neste texto, propõe-se o conceito de medialidade tanto para designar o "palco político e ético" como o "espaço ontológico" que a dança potencia. A emergência deste mesmo conceito justifica-se, segundo a argumentação da autora, pela expansão de fronteiras a que se assiste na história da dança, decorrente de uma rutura que transforma o corpo e a performatividade numa instância relacional particularmente tensiva e discursiva. Depois de uma discussão e análise relativa às especificidades do meio, às limitações e possibilidades da transmedialidade, tendo por objeto as produções operísticas, bem como de uma reflexão de natureza autopoiética sobre as transformações operadas na dança, os dois outros textos que se juntam a este primeiro momento hermenêutico, ou grupo de textos, propõem por sua vez o pensamento crítico potenciado pelo teatro, na sua vertente assumidamente política e interventiva. Trata-se de dois estudos de caso, os quais passamos a apresentar. "Monstros, máquinas e pipocas: teatro do oprimido e protesto de rua", da autoria de Inês Barbosa e Fernando Ilídio Ferreira, procura levar-nos a refletir sobre as possibilidades de se pensar a crise europeia, ou melhor, a crise em Portugal, a partir das provocações performativas e protesto de rua do designado, precisamente, "teatro do oprimido". Neste artigo, o Teatro do Oprimido é discutido "enquanto ferramenta de ação coletiva e educação crítica, no âmbito das mobilizações sociais contemporâneas", nomeadamente tendo em vista estimular uma reflexão mais profunda (no seu papel potenciador da intervenção e da participação) sobre os limites do atual sistema capitalista. Segue-se mais um estudo, denominado "House on Fire: um caso de arte política e colaborativa", reportado no texto de Teresa Mora. O modo como as práticas artísticas potenciam atualmente "a transição para um modelo colaborativo entre cultura artística e cultura científico-social e filosófica" é a principal tese que neste artigo se procura defender. Para tal, a autora baseia-se na análise e discussão de materiais (planos de atividade e programas) relativos à ação da rede europeia de teatros e festivais, designada House on Fire, entre 2012 e 2015. 
Num segundo momento, nesta publicação apresenta-se mais um conjunto de quatro textos, incidentes sobre o cinema, a fotografia, a pintura e as artes visuais. A partir de diferentes abordagens, problemáticas e metodologias de análise, são ensaiadas as múltiplas implicações culturais na produção artística cinematográfica e visual, nos modos de perceber e de dar a ver. Caterina Cucinotta, por meio do seu artigo intitulado "Percursos de análise do vestuário em filmes portugueses de etnofiç̧ão", propõe-se operacionalizar o conceito de etnoficção através da análise de três trilogias do cinema português. Inquirir sobre as especificidades do vestuário cinematográfico português, em articulação com a teoria da moda e uma dada narrativa etnográfica e cultural é o propósito do referido artigo. Por seu turno, Eliza Bachega Casadei e Mariana Duccini, no seu artigo - "Objetos da violência: as formas do pathos nas composições de Yael Martinez, Glenna Gordon e Eugênio Grosso" -, problematizam a iconologia dos objetos de consumo, interrogando o modo como os três fotógrafos em causa operam determinadas estratégias de composição visual. A violência é o tema comum que atravessa as obras analisadas, sendo diversas as formas do pathos evocadas. Deste segundo conjunto faz ainda parte o texto intitulado "Sobre o 'Jardim das Delícias' como modelo de análise dos processos de comunicação intercultural", de Lurdes Macedo. Tendo por base a obra pictural referenciada no título, e perspetivando-a do ponto de vista da comunicação intercultural, a autora visa propor uma leitura capaz de contribuir para a desfragmentação da memória coletiva, ancorada nas trajetórias globais, nomeadamente nas navegações intercontinentais, nas quais portugueses e espanhóis tiveram um especial protagonismo. Completando este segundo grupo de textos, Sílvia Pinto e Moisés de Lemos Martins apresentam "Lógicas de vinculação na arte". Abordando a metafísica da imagem, numa perspetiva histórica, este artigo argumenta no sentido de uma aproximação da arte à religião. No contexto da atualidade, os autores procuram "mostrar a importância da arte e da sua ascendência mítico-religiosa na redefinição da imagem mediática".

Por fim, segue-se um terceiro momento, entretecido pela ligação entre a arte e a tecnologia. Trata-se de um conjunto de três textos. Em primeiro lugar, inclui-se nele o artigo intitulado "Mídia, arte e tecnologia: uma reflexão contemporânea", da autoria de Fernando Augusto Silva Lopes. Qual o papel da tecnologia na massificação mediática e mercantilização da cultura e das artes na contemporaneidade? Esta é a questão que o autor procura discutir, bem como as suas implicações nas mudanças culturais e sociais no tempo presente. $\mathrm{O}$ modo como as práticas artísticas evidenciam e interrogam a influência dos media, e do mercado, é igualmente um dos tópicos que o texto tenta esclarecer. Focalizado na realidade da indústria fonográfica brasileira, segue-se o texto de Daniel Ferreira Wainer, precisamente intitulado "Entre arte e tecnologia: condições de existência e funcionamento da indústria fonográfica brasileira no século XXI". Com base numa investigação empírica, o autor reflete sobre os efeitos, as ruturas e as continuidades implicados na digitalização. Questões como a pirataria ou os direitos autorais são objeto dessa mesma reflexão. Acrescenta-se ainda o texto de Pedro Andrade, "Comunicação da arte pela investigação aberta: sobre políticas culturais, património e receção da inovação na arte". Neste artigo, são apresentados conceitos fundamentais 
à comunicação da arte e à comunicação pública da arte, onde as novas tecnologias desempenham um papel particular, nomeadamente em questões como a literacia artística. Trata-se de um texto que não deixa de sugerir recomendações práticas para a pesquisa nestas áreas (por via da investigação aberta), propondo mesmo uma agenda e anexando ainda um glossário sobre a especialidade temática.

A secção dos artigos encerra com um texto de Ludovic Chatenet e Anne Beyaert-Geslin, o qual esclarece, precisamente, a articulação temática (comunicação e arte) respeitante a este número da revista. Intitulado "Da comunicação à arte: o McDonald's e o flat design", este artigo incide sobre uma análise semiótica dos anúncios da campanha publicitária de 2015 da McDonald's criada pela agência TBWA, em Paris. Com base na referida análise, os autores sugerem uma nova retórica da imagem, segundo a qual "as sociedades de hoje, definidas como hipermodernas, já não transacionam objetos, mas antes formas de vida e valores de subscrição a comunidades de utilizadores". A compreensão desta mudança de paradigma convoca, oportunamente, uma interrogação sobre a esteticização, bem como sobre a "artistização", de que se entretece a cultura contemporânea.

Resta referir a segunda secção deste número temático, onde se inclui uma recensão crítica da autoria de Anabela Veloso Rodrigues, sobre uma recente publicação de Luís Ferreira Alves, onde se explana o papel da fotografia na obra arquitetónica de Eduardo Souto de Moura.

É com este itinerário, aqui levemente antecipado, que deixamos o nosso convite à leitura que se segue, certas de que pensar e investigar sobre a arte-comunicação é hoje uma das muitas promissoras possibilidades de se (des) construir conhecimento...

\section{NotAs BiográFicAs}

Helena Pires é Professora Auxiliar no Departamento de Ciências da Comunicação, no Instituto de Ciências Sociais da Universidade do Minho, e investigadora no Centro de Estudos de Comunicação e Sociedade (CECS) da mesma Universidade.

Doutorou-se em 2007, em Semiótica da Comunicação, na referida instituição e desenvolve investigação nas áreas da Semiótica e Cultura Visual, Cultura Urbana e Publicidade, tendo nomeadamente desenvolvido pesquisa sobre a temática da Paisagem e sua representação na arte contemporânea. Mais recentemente, é co-coordenadora do Projeto, inscrito no CECS, Passeio. Plataforma de artes e cultura urbana. Leciona disciplinas tais como Semiótica, Publicidade e Arte, Media e Comunicação, entre outras. É atualmente membro da Direção do Mestrado de Comunicação, Arte e Cultura.

E-mail: hpires@ics.uminho.pt

Departamento de Ciências da Comunicação, ICS, Universidade do Minho, Campus de Gualtar, 4710-057 Braga, Portugal

Silvana Mota Ribeiro é Professora Auxiliar do Instituto de Ciências Sociais da Universidade do Minho. Leciona nas áreas da cultura e semiótica visuais, arte, moda e 
comunicação estratégica. Desenvolve investigação na área dos discursos de género, análise de imagem, semiótica social e multimodalidade. É atualmente membro da Direção do Mestrado de Comunicação, Arte e Cultura.

E-mail: silvanar@ics.uminho.pt

Departamento de Ciências da Comunicação, ICS, Universidade do Minho, Campus de Gualtar, 4710-057 Braga, Portugal

Anne Beyaert-Geslin é professora de semiótica e comunicação na Universidade Bordeaux-Montaigne e diretora da equipa de pesquisa MICA (Mediations, Information, Communication, Arts). Editou dezasseis livros coletivos e foi revisora de diversas edições (em 2017 com Maria Giulia Dondero e Audrey Moutat, Les plis de imagem, Reflexivité et énonciation dans l'image, Lambert Lucas) e 4 livros: L'image préoccupée, Hermès-Lavoisier, 2009; Sémiotique du design, Presses Universitaires de France, 2012 (tradução italiana em 2017: Semiotica del design, Rimini, Edição ETS); Sémiotique des objets, la matière du temps, Presses Universitaires de Liège, colecção Sigilla, 2015. Méthodes du portrait será publicado por De Boeck ainda em 2017.

A autora também escreveu cerca de 120 artigos em semiótica de imagem, média e design em francês, italiano, espanhol, inglês, chinês, português e persa.

E-mail: anne.geslin-beyaert@u-bordeaux-montaigne.fr

Bordeaux-Montaigne University. Domaine Universitaire, 19 esplanade des Antilles, 33607 Pessac, France 